\title{
The Characteristics of Perlite Sound Absorption Board Formed By Vibration Molding
}

\author{
Xiao Yanjun*, Liu Rui, Song Haiping, Jing Ran and Zhu Jiayu \\ School of Mechanical Engineering, Hebei University of Technology, Tianjin, 300130, P.R. China
}

\begin{abstract}
This paper puts forward a scheme to form perlite sound absorption boards by vibration molding according to the material properties and the characteristics of vibration forming method. In the trial, the feasibility and reliability of this method were confirmed by studying the effect of working pressure, frequency and vibration force on the quality of the perlite sound absorption board. Besides, a series of recommended parameters for better forming was proposed. Through the discussion on the characteristics of the perlite sound absorption board after vibration molding, it is verified that different molding methods have a great influence on the quality and performance of the perlite sound absorption board. In addition, the conclusion which provides a basis for further research on forming method of similar boards shows that the density of the finished products formed by vibration molding method is more uniform.
\end{abstract}

Keywords: Perlite, sound absorption board, vibration molding, vibration force, working pressure.

\section{INTRODUCTION}

Combining the functions of sound absorption, fire prevention, thermal insulation, heat insulation, etc., perlite sound absorption board is a kind of new building material which has a broad market prospect [1]. With the aggregate of expanded perlite, configured with inorganic adhesive as well as curing agents, perlite sound absorption board is usually formed by extrusion molding and drying processes.

With the increasing market requirements of perlite sound absorption board, it is an urgent need to solve the problems in production process. For example, with the increase of the thickness of products, the density and uniformity of the edges of the sound absorption boards will be reduced to a certain extent. So, the requirements of the spreading process and pressure as well as time in molding process are set to be much higher, making the production process more complex and the production efficiency much lower. This paper started from the principle of vibration molding and combined it with the characteristics of raw materials and production process of perlite sound absorption board to put forward a new method to form perlite sound absorption board by vibration molding. In addition, the influence of vibration parameters on molding effect and the characteristics of the products were summarized through the analysis of simulation results.

\section{THE VIBRATION MOLDING PRINCIPLE OF PERLITE SOUND ABSORPTION BOARD}

\subsection{The Principle and Application of Vibration Molding}

Vibration molding is a common method for concrete brick and other building material and the principle of it is

\footnotetext{
*Address correspondence to this author at the School of Mechanical Engineering, Hebei University of Technology, Tianjin, 300130, P.R. China; Tel: 13388007288; E-mail: x_yanjun2009@163.com
}

making the cementitious particles as well as the coarse and fine aggregates dense at high frequency vibration and pressure [2]. In the vibration process, the crushed particles transit from initial static state to the moving state and the friction among the pressed materials transits from static friction state to dynamic friction state so that the friction resistance among material particles reduces greatly. Meanwhile, the pressure on the surface of the materials makes the small particles rapidly fill into the gaps among large particles through extrusion and deformation. Little energy consumption can reach the effect of high density in the whole vibration molding process [3]. The vibration exciter engenders vibration energy and the vibration platform transfers it into the materials by molds or die boxes and other intermediate auxiliary equipment. In the actual production forming blocks or boards of different shapes and specifications, the size and ratio of material particles are also different so that the vibration parameters should be set according to the specific situation.

\subsection{The Physical Material Properties of Perlite Sound Absorption Board}

Research shows that the most influential factors to the sound absorption coefficient of sound absorption materials are density, admixture of expanded perlite, gradation, etc. This paper set the perlite sound absorption boards produced by a Chengde company as an example to analyze the physical characteristics of the raw materials. This company used ordinary Portland cement and light porous expanded perlite as main raw materials with a good gradation. The main physical properties of the raw materials are shown in Table $\mathbf{1 .}$

\section{THE MECHANICAL ANALYSIS OF PERLITE VIBRATION MOLDING SYSTEM}

The vibration molding process of perlite sound absorption board is consistent with the traditional one including sifting the mixture of raw materials, weighing, spreading, vibration molding and demoulding. 
Table 1. The physical properties of expanded perlite.

\begin{tabular}{|c|c|c|}
\hline \multicolumn{2}{|c|}{ Bulk density $/ \mathrm{kg} / \mathrm{m}^{3}$} & 79 \\
\hline \multicolumn{2}{|c|}{ Moisture content $/ \%$} & 0.5 \\
\hline \multicolumn{2}{|c|}{ Water Absorption /\% } & 62 \\
\hline \multicolumn{2}{|c|}{ Thermal Conductivity/[w/(m·k)] } & 0.41 \\
\hline \multirow{4}{*}{ Gradation/\% } & $>1.18$ & 37.2 \\
\hline & $0.6 \sim 1.18$ & 53.2 \\
\hline & $0.3 \sim 0.6$ & 6.1 \\
\hline & $<0.3$ & 3.5 \\
\hline
\end{tabular}

A biaxial inertial vibration molding platform was used for this molding machine and the inertia force diagram is shown in Fig. (1) as follow. This figure shows that the force effecting on the vibration molding machine were only the inertial force $\mathrm{F}_{\mathrm{H}}$ caused by the movement of the machine and the inertial force $2 \mathrm{~F}$ caused by the movement of eccentric subs. They balanced each other [4].

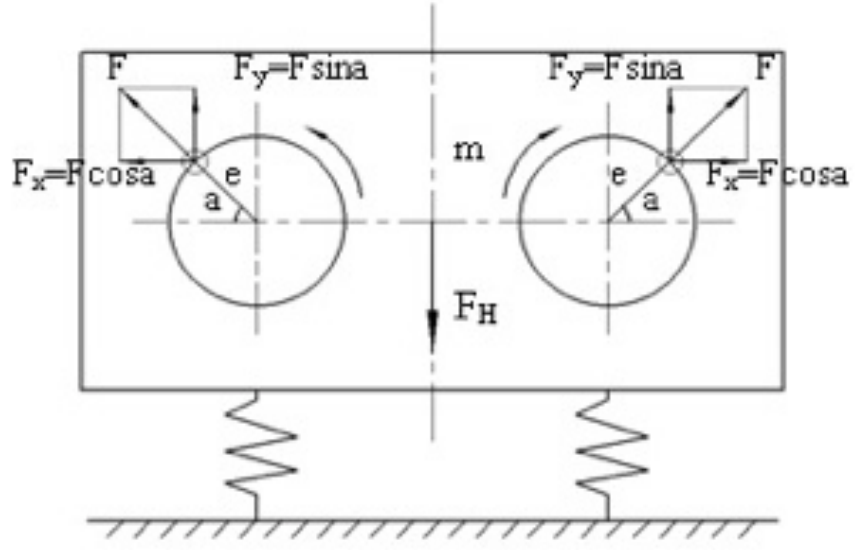

Fig. (1). Inertial force diagram of the biaxial vibration platform.

That is: $\mathrm{F}_{\mathrm{H}} \approx 2 \mathrm{~F}$

$\mathrm{F}_{\mathrm{H}}=\mathrm{m} \omega^{2} \mathrm{ASin} \alpha$

In the formulas:

$\mathrm{F}_{\mathrm{H}}$-the vibration force when the machine moves $(\mathrm{N})$

$\mathrm{m}$ - the quality of the vibration machine (including the weight of the eccentric subs) $(\mathrm{kg})$

$\omega$ - the vibration frequency $(\mathrm{rad} / \mathrm{s})$

$\mathrm{n}$ - the speed of the rotary axis ( $\mathrm{r} / \mathrm{min})$

A - the amplitude (m)

$\alpha$-the phase angle $\left(^{\circ}\right), \alpha=\omega \mathrm{t}$

$\mathrm{F}=\mathrm{m}_{0} \omega^{2} \mathrm{eSin} \alpha$

$\mathrm{F}$ - the vibration force when single eccentric sub moves (N)

$\mathrm{m}_{0}$ - the weight of the eccentric sub $(\mathrm{Kg})$

e- the distance between the center of gravity of the eccentric sub and the rotary axis (m)

Substitute Formulas 2 and 3 into Formula 1:
$\mathrm{A} \approx \frac{2 \mathrm{~m}_{0} e}{m}$

Fig. (1) shows that the inertial force of the eccentric subs in horizontal direction $F_{x}$ had equal value and opposite direction which could cancel each other out whatever angle the eccentric subs turns to [5]. But the component forces in vertical direction superimposed on each other acting on the vibration platform. So it could be introduced from Formula 1 that:

$\mathrm{F}_{\mathrm{H}} \approx 2 \mathrm{~F}$

and:

$\mathrm{F}_{\mathrm{y}}=\mathrm{F} \sin \alpha$

When the vertical force $\mathrm{F}_{\mathrm{y}}$ reached the maximum value (the phase angle is $0^{\circ}$ ), substitute Formulas 3 and 6 into Formula 5 and the amplitude of vibration force of the biaxial vibration was calculated:

$\mathrm{F}_{\mathrm{H}} \approx \frac{2 \mathrm{G}_{0} \bullet \mathrm{e} \bullet n^{2}}{91.2}$

According to Formula 7, the required vibration force was calculated.

\section{EFFECTS OF VIBRATION PARATMETERS ON MOLDING EFFECT}

According to the analysis of vibration molding process and vibration force, a kind of perlite sound absorption board of $600 \mathrm{~mm} \times 600 \mathrm{~mm} \times 50 \mathrm{~mm}$ was set an example to conduct the vibration molding test on the raw materials in order to check the feasibility of this forming method and the effects of different vibration parameters on molding process and the quality of the products.

\subsection{The Working Pressure}

In the vibration molding process, the working pressure of the upper die has a great effect on the quality of the product [6]. So in the conditions of same vibration force and frequency, the effect of different working pressure on the quality of the products was tested first. Set the frequency 30 $\mathrm{Hz}$ and set the angle of the eccentric subs $60^{\circ}$ to gain the corresponding vibration force. Adjust the working pressure of the upper die and set it $10 \mathrm{MPa}, 13 \mathrm{MPa}, 16 \mathrm{MPa}, 19$ $\mathrm{MPa}, 22 \mathrm{MPa}$ in proper order. The result was obtained as shown in Table 2 according to the quality of the products and springback state of the materials in molding process.

Table 2. Effect of working pressure on vibration molding effect.

\begin{tabular}{|l|c|c|c|c|c|}
\hline Working pressure/MPa & 1 & 5 & 10 & 15 & 20 \\
\hline Amplitude /mm & 3.71 & 3.24 & 3.42 & 2.89 & 2.62 \\
\hline Time to springback/s & 280 & 164 & 128 & 105 & 85 \\
\hline
\end{tabular}

Meanwhile, the density of sound absorption board formed by vibration molding was detected as the result shown in Fig. (2). 


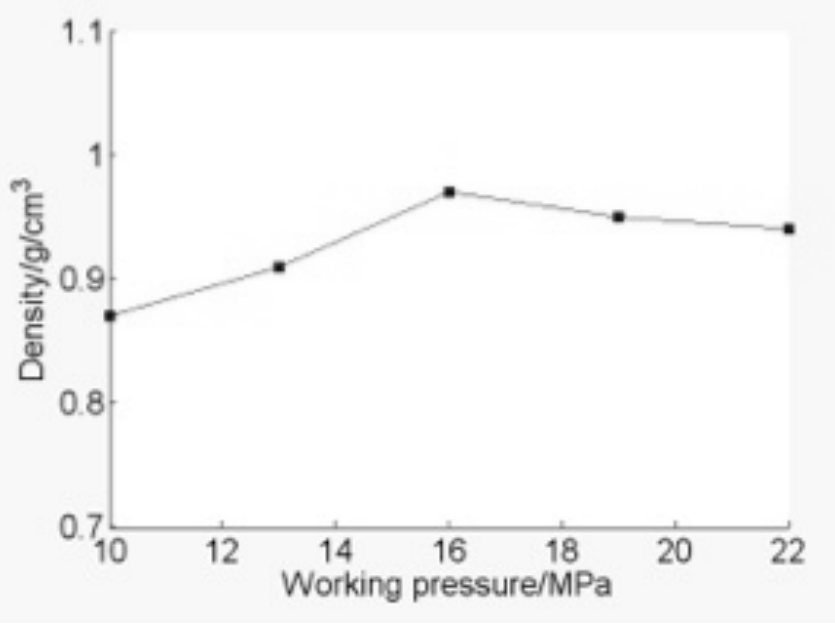

Fig. (2). The relationship between density and working pressure.

\subsection{The Frequency}

The frequency is an important parameter effecting vibration molding process. When the vibration frequency is consistent with the natural frequency of raw materials, the resonance occurs and the molding effect is good [7]. The raw material of the sound absorption board is mainly composed of expanded perlite and Portland cement with a natural frequency ranging from $20 \mathrm{~Hz}$ to $35 \mathrm{~Hz}$. According to the test result in Table 2 and taking the range of frequency of vibration molding machine into consideration, set the working pressure $16 \mathrm{MPa}$ and conduct the test under different vibration frequencies $(20 \mathrm{~Hz}, 25 \mathrm{~Hz}, 30 \mathrm{~Hz}, 35 \mathrm{~Hz})$. The test result is shown in Table $\mathbf{3}$ as follow.

Table 3. Effect of frequency on vibration molding effect.

\begin{tabular}{|l|c|c|c|c|}
\hline Frequency/Hz & 20 & 25 & 30 & 35 \\
\hline Density/(g/cm $\left.{ }^{3}\right)$ & 0.83 & 0.91 & 0.97 & 1.01 \\
\hline Time to springback/s & 128 & 120 & 72 & 46 \\
\hline
\end{tabular}

It can be seen in Table 3 that, with the increase of frequency, the density of the products increased and the time to springback decreased. When the frequency was set $20 \mathrm{~Hz}$ or $25 \mathrm{~Hz}$, the time to springback was relatively longer which did not meet the good vibration state. When the frequency was $35 \mathrm{~Hz}$, the time to springback was too short to have a good effect on molding and the amplitude was very large that may cause the shake of the machine. Therefore, considering the fluctuation range, the frequency can be set from $28 \mathrm{~Hz}$ to $32 \mathrm{~Hz}$ and $30 \mathrm{~Hz}$ is most recommended.

\subsection{The Vibration Force}

Under the same pressure and frequency, changing the angle of the eccentric subs, the effect of vibration force on molding effect can be informed. Based on the former results about the effects of different pressures and frequencies on molding tests, set the vibration pressure $16 \mathrm{MPa}$ to conduct the test of raw materials when the angle of the eccentric subs were set $0^{\circ}, 30^{\circ}, 60^{\circ}, 90^{\circ}$ and $120^{\circ}$ in proper order. The result was obtained as shown in Table 4.
Table 4. Effect of vibration force on vibration molding effect.

\begin{tabular}{|l|c|c|c|c|c|}
\hline Angle of Eccentric Subs $/\left(^{\circ}\right)$ & 0 & 30 & 60 & 90 & 120 \\
\hline Vibration force/N & 7866 & 7602 & 6818 & 5602 & 4019 \\
\hline Density/(g/cm $\mathbf{3})$ & 0.968 & 0.963 & 0.961 & 0.937 & 0.916 \\
\hline Amplitude/mm & 3.51 & 3.42 & 3.28 & 3.05 & 2.97 \\
\hline
\end{tabular}

It can be seen from Table $\mathbf{4}$ that the density of the products increased with the increase of the vibration force. But the rate of increase became smaller gradually. After the vibration force reached $6818 \mathrm{~N}$ (the angle of the eccentric subs was $60^{\circ}$ ), the influence of increasing vibration force on the density was no longer significant and the increase of amplitude was not conducive to the stability of the system [8]. Therefore, considering the fluctuation range and the relationship between vibration force and density, the vibration force can be set from $6000 \mathrm{~N}$ to $8000 \mathrm{~N}$ and 6818 $\mathrm{N}$ (the angle of the eccentric subs is $60^{\circ}$ ) is most recommended.

\subsection{Rational Allocation of the Vibration Parameters}

According to the tests above on vibration molding process to form perlite sound absorption board and taking relevant data as reference, the better conditions without large amplitude and short vibration time can be concluded: setting the working pressure $13 \mathrm{MPa}$ to $19 \mathrm{MPa}$, the vibration force $6000 \mathrm{~N}$ to $8000 \mathrm{~N}$ and the frequency $28 \mathrm{~Hz}$ to $32 \mathrm{~Hz}$. It is most recommended to set the working pressure $16 \mathrm{MPa}$, the vibration force $6818 \mathrm{~N}$ and the frequency $30 \mathrm{~Hz}$.

\section{PERFORMANCE ANALYSIS OF THE PRODUCTS BY VIBRATION MOLDING}

The products of sound absorption board by vibration molding are shown in Fig. (3) as follow. It can be seen from the exterior view that the pattern is clear and the edges are neat. Taking the previous theoretical analysis and relevant literatures about vibration molding as reference, the product formed by vibration molding should have a more uniform density and a better compactness compared with the products formed by other methods. Therefore, this paper checked the densities of both the products and compared the results to verify the conclusion.

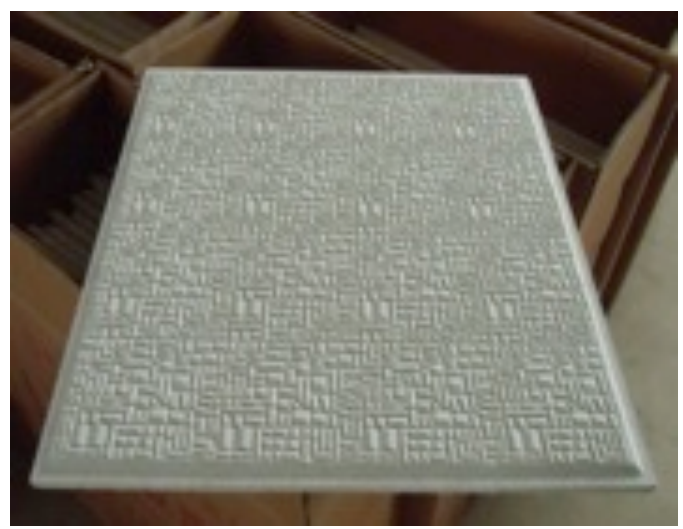

Fig. (3). The sound absorption board formed by vibration molding. 
Split the products formed by ordinary method and vibration molding as the way shown in Fig. (4) and label each part. Measure the density of each part respectively, and the densities of two sound absorption boards can be obtained as shown in Fig. (5).

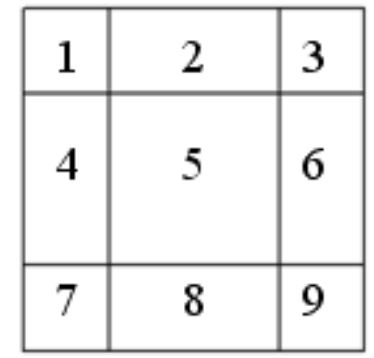

Fig. (4). The way to split and label the products.

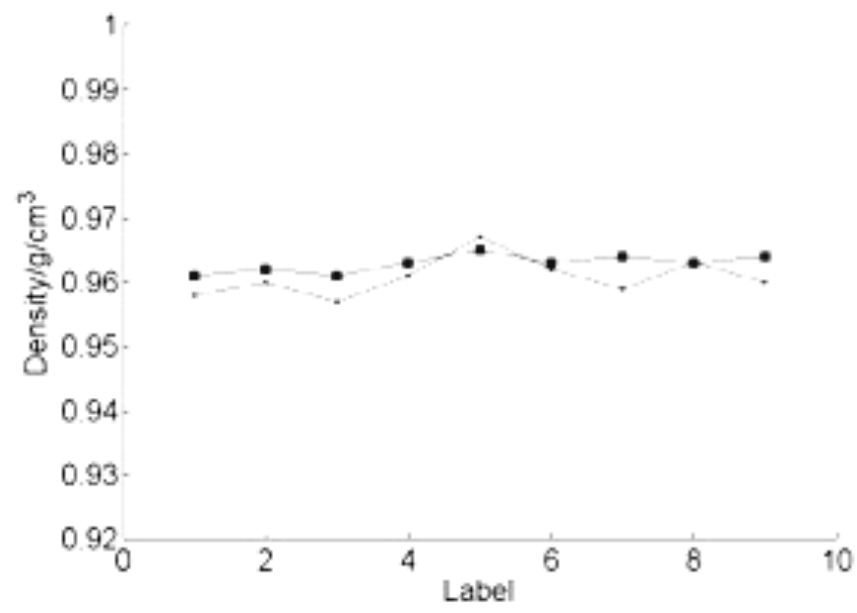

Fig. (5). The densities of the products formed by different method.

The test results show that the density of each part of the product formed by vibration molding was more uniform while the product formed by ordinary method had a higher density in the middle and fluctuant densities on the edges. It can be included that the method of vibration molding makes the raw materials flow and spread more evenly ending up with a uniform distribution of porous and particles. According to other researches and experiences, there is a direct relationship between the density of the materials and the detection formula of the effect of sound absorption. Therefore, the more uniform the density is, the better the effect of sound absorption is. In addition, the product with a uniform density is relatively lighter. Thus it can be observed that different forming methods have different influence on the quality and performance of the perlite sound absorption boards.

\section{CONCLUSION}

According to the material properties and the characteristics of vibration forming method, this paper put forward a scheme to form perlite sound absorption boards by vibration molding. In the trial, the feasibility and reliability of this method were confirmed by studying the effect of pressure, frequency and vibration force on the quality of the perlite sound absorption board and a series of recommended parameters better to forming was proposed. In addition, through the discussion on the characteristics of the perlite sound absorption board after vibration molding, it was verified that the perlite sound absorption board formed by vibration molding has a more uniform density and better effect of sound absorption than that formed by ordinary methods. This conclusion provides a basis for further research on forming method of similar boards.

\section{CONFLICT OF INTEREST}

The authors confirm that this article content has no conflict of interest.

\section{ACKNOWLEDGEMENTS}

Declared none.

\section{REFERENCES}

[1] Wang Y. Analysis of the performance of cement based expanded perlite. Construct Technol Low Temp 2011; 8: 13-4.

[2] Wang L, Xie X, Luan H. Influence of compacting methods on grade macadam shear characteristics. J Highway Transportat Res Dev 2008; 25(5): 40-4.

[3] Sha A, Chen K, Ma F. Indoor test on physical-mechanical properties of loess under vibration compaction. J Chang'an Univ (Nat Sci Ed) 2008; 28(1): 1-5.

[4] Zhao C, Wang L, Ren J, et al. Self-synchronization of two identical exciters in a resonant vibrating system. J NE Univ Nat Sci 2012; 12: 1754-7.

[5] Wang X. The determination of amplitude and vibration direction of linear excitation force vibrating machinery equipment. J China Coal Soc 2003; 1: 167-70.

[6] Chen K, Sha A. Research on resilient modulus test of compacted loess. Rock Soil Mech 2012; 31(3): 748-52.

[7] Zheng G, Huo H, Lei H. Comparative experiment on vibrating compaction and modified proctor compaction of performance of graded crushed aggregate. J Tianjin Univ 2003; 1: 38-43.

[8] Wang L, Xie X, Li C. Comparative experiment on vibrating compaction and modified proctor compaction of performance of graded crushed aggregate. China J Highway Transport 2007; 20(6): 19-24. 